\title{
Epidemiology
}

\section{Effect of selective vaccination on rubella susceptibility and infection in pregnancy}

\author{
CHRISTINE L MILLER, ELIZABETH MILLER, PETER J L SEQUEIRA, \\ JOHN E CRADOCK-WATSON, MAURICE LONGSON, ELIZABETH C WISEBERG
}

\begin{abstract}
The effect of school and adult vaccination on susceptibility to rubella in women of childbearing age was assessed in the Manchester area, where the population attending antenatal clinics is over 40000 a year. Between 1979 and 1984 the proportion susceptible fell from $6 \cdot 4 \%$ to $2 \cdot 7 \%$. In $1984,4 \cdot 2 \%$ of nulliparous women were susceptible compared with $1.4 \%$ of women in their second or subsequent pregnancy. Eighty five per cent of pregnant women screened and found to be non-immune were vaccinated post partum before leaving hospital. Requests for prevaccination screening of non-pregnant women increased in response to a national campaign and at the time of local outbreaks of rubella but only two thirds of those found to be nonimmune were subsequently vaccinated. During 1983 and 1984 infection was confirmed in 57 pregnant women-2\% of those non-immune.

Selective vaccination has reduced susceptibility to rubella in the childbearing population, but it is suggested that mass vaccination of children of both sexes should be added to the existing policy to control circulation of wild rubella virus and reduce the risk of infection to pregnant women who remain susceptible.
\end{abstract}

\section{Introduction}

Selective vaccination of schoolgirls against rubella began in the United Kingdom in $1970^{1}$ with the ultimate aim of eliminating congenital rubella syndrome. ${ }^{23}$ In 1972 vaccination after serological screening was also offered to women of childbearing age before pregnancy or after delivery. ${ }^{4}$ In 1976 acceptance of vaccine by schoolgirls in England and Wales was only $72 \%{ }^{5}$; vaccination figures for adult women were unknown. A widespread outbreak of rubella in 1978-9 resulted in 124 notified cases of congenital rubella syndrome ${ }^{6}$ and 1405 terminations for rubella ${ }^{78}$ - a sixfold rise from

PHLS Communicable Disease Surveillance Centre, London NW9 5HT CHRISTINE L MILLER, MFCM, senior epidemiologist ELIZABETH MILLER, $M B$, BS, senior microbiologist

Central Serology Laboratory, Withington Hospital, Manchester M20 8LR PETER J L SEQUEIRA, MB, BS, laboratory director ELIZABETH C WISEBERG, SRN, sister, rubella study

Public Health Laboratory, Withington Hospital, Manchester JOHN E CRADOCK-WATSON, BM, BCH, senior medical microbiologist

Booth Hall Children's Hospital, Manchester M92AA

MAURICE LONGSON, MD, consultant virologist

Correspondence and requests for reprints to: $\operatorname{Dr} C L$ Miller.
1976-7. As a consequence doctors were urged to increase the uptake of vaccination, ${ }^{9}$ and by 1980 acceptance at school age had risen to $84 \% .{ }^{10}$ Concern about the impending outbreak of rubella in spring 1983 prompted further action by the Department of Health and $O$ Social Security, ${ }^{11}{ }^{12}$ and in November 1983 a campaign was launched with widespread publicity to increase both adult and school vaccination over a period of three years. ${ }^{213} \mathrm{~A}$ study coordinated by $\infty$ the then Epidemiological Research Laboratory (now the Com- 은 municable Disease Surveillance Centre) of the Public Health $\vec{\sigma}$ Laboratory Service (PHLS) was set up to assess the impact already $Z$ made by rubella vaccination on the susceptibility of women of childbearing age and to monitor future changes resulting from the $\frac{\mathbb{\Phi}}{3}$ campaign.

In Britain screening for rubella antibody is part of the routine antenatal examination, and in most areas women are screened in $\vec{\oplus}$ each pregnancy irrespective of past immunity or vaccination. The effects of school, prepregnancy, and postpartum vaccination were 0 assessed by comparing susceptibility among pregnant women with that of men in the same age groups. Since non-pregnant women are also screened before vaccination the immediate effect of the campaign was monitored by recording the number of these requests $\frac{}{\Phi}$ before and after the campaign began. The overall value of screening pregnant and non-pregnant women was assessed by checking the proportion of non-immune women who were subsequently vaccinated. The incidence of confirmed rubella in the population of pregnant women was measured using the laboratory results of diagnostic investigations for rubella.

The study began in Greater Manchester in January 1984 and in PHLS laboratories in Ashford, Bristol, Gloucester, Hereford, Leeds, Luton, and Reading during the year. The total number of serum samples tested for rubella in these laboratories in 1984 was $\delta$ roughly 170000 , of which about 104000 were from pregnant women. This report gives the results from Manchester for 1984 .

\section{Subjects and methods}

In the Manchester area the Central Serology Laboratory screens about 40000 serum samples a year from patients attending antenatal clinics at $14 \mathrm{~W}$ hospitals in the North Western and Mersey regions. The Manchester Public Health Laboratory and North Manchester Regional Virus Laboratory teste serum samples for prevaccination screening of non-pregnant women and for diagnostic purposes. Samples are screened by radial haemolysis and those $\stackrel{S}{\rightarrow}$ giving zone diameters corresponding to 15 IU or less retested by haemag- $\square$ glutination inhibition. Seronegativity is defined as radial haemolysis $<15$ IU and haemagglutination inhibition titre $<20$. In the Central Serology $\mathbb{D}$ Laboratory and Manchester Public Health Laboratory vaccination is also recommended for those with haemagglutination inhibition titres of $<40$.

From January 1984 information on parity (number of previous births) was requested for patients attending antenatal clinics at seven of the hospitals $\Omega$ and from June 1984 for all 14 hospitals. About 1000 men matched for age with the pregnant population and attending clinics for sexually transmitted diseases in the Manchester area in 1984 were also screened for rubella by the $\frac{\vec{Q}}{\partial}$ 
Central Serology Laboratory. At the Manchester Public Health Laboratory and North Manchester Regional Virus Laboratory details of all requests for screening non-pregnant patients were recorded by month throughout 1983 and 1984. A study nurse (ECW) was appointed to check postpartum vaccination, and non-pregnant women requiring vaccination were followed up from the Manchester Public Health Laboratory and North Manchester Regional Virus Laboratory. The number of serum samples tested from patients with suspected rubella or after contact was recorded by month in each laboratory throughout 1983 and 1984. For each woman infected in pregnancy information on parity, vaccination history, and outcome of pregnancy was sought.

\section{Results}

\section{ANTENATAL SCREENING}

To compare data for 1984 with those from previous years Central Serology Laboratory computer records were analysed from 1979 to 1983 . Over that period the proportion of pregnant women who were seronegative fell from $6 \cdot 4 \%$ to $3 \cdot 5 \%$; in 1984 it fell again to $2 \cdot 7 \%$ (table I). The fall was similar in all age groups.

TABLE I-Results of serological screening for rubella antibody in pregnant women in Manchester, 1979-84

\begin{tabular}{lcccccc}
\hline & 1979 & 1980 & 1981 & 1982 & 1983 & 1984 \\
\hline $\begin{array}{l}\text { No tested } \\
\text { W With haemagglutination } \\
\text { titre }<20\end{array}$ & $23799 \star$ & 43981 & 43328 & 45556 & 42958 & 40017 \\
\hline
\end{tabular}

* Half year.

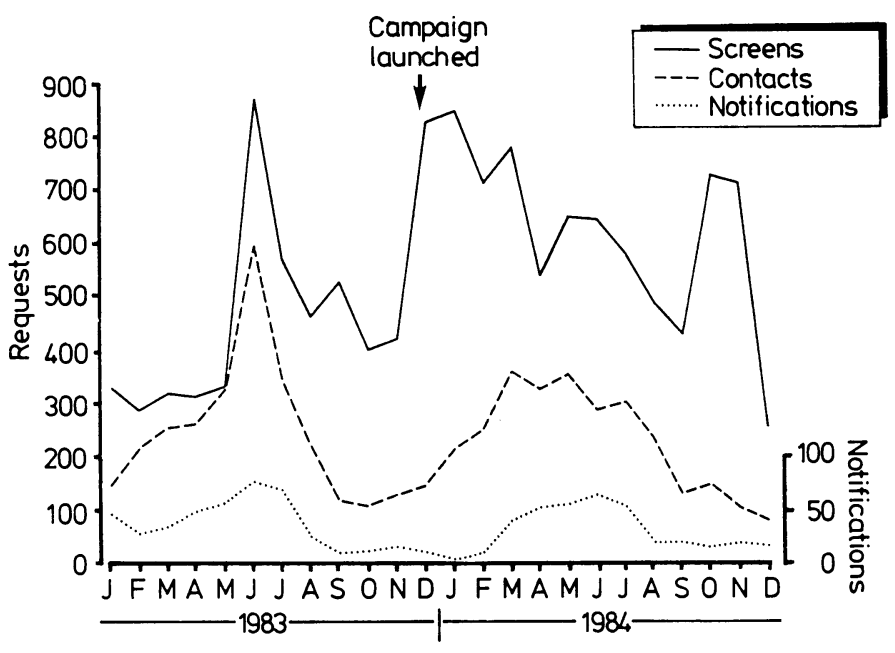

FIG 2-Requests for prevaccination screening and contact testing, and notifications of rubella in Manchester during 1983-4. (Rubella is notifiable in Bristol, Exeter, Leeds, Manchester, and Newcastle.)

\section{SCREENING OF NON-PREGNANT WOMEN}

In 1984 a total of 11415 serum samples from non-pregnant women were screened by the Manchester Public Health Laboratory and North Manchester Regional Virus Laboratory. Of these, $41 \%$ were routine pre-employment screens requested by occupational health clinics, $32 \%$ came from general practitioners, $8 \%$ from family planning clinics, and $19 \%$ from other sources including gynaecology wards and infertility clinics. Of the 4741

TABLE II-Proportions of pregnant and non-pregnant women in various age groups screened in 1984 and found to have haemagglutination inhibition titres of $<20$

\begin{tabular}{|c|c|c|c|c|c|c|c|c|c|c|}
\hline & \multicolumn{2}{|c|}{ Age $15-19$} & \multicolumn{2}{|c|}{ Age $20-24$} & \multicolumn{2}{|c|}{ Age $25-29$} & \multicolumn{2}{|c|}{ Age $\geqslant 30$} & \multicolumn{2}{|c|}{ Total } \\
\hline & No tested & $\begin{array}{c}\text { No (\%) with } \\
\text { titre }<20\end{array}$ & No tested & $\begin{array}{l}\text { No (\%) with } \\
\text { titre }<20\end{array}$ & No tested & $\begin{array}{c}\text { No (\%) with } \\
\text { titre }<20\end{array}$ & No tested & $\begin{array}{l}\text { No (\%) with } \\
\text { titre }<20\end{array}$ & No tested & $\begin{array}{c}\text { No }(\%) \text { with } \\
\text { titre }<20\end{array}$ \\
\hline $\begin{array}{l}\text { Pregnant } \\
\text { Non-pregnant }\end{array}$ & $\begin{array}{l}6497 \\
1188\end{array}$ & $\begin{array}{l}228(3 \cdot 5) \\
113(9 \cdot 5)\end{array}$ & $\begin{array}{r}13486 \\
2107\end{array}$ & $\begin{array}{l}360(2 \cdot 7) \\
159(7 \cdot 5)\end{array}$ & $\begin{array}{r}11929 \\
1980\end{array}$ & $\begin{array}{l}282(2 \cdot 4) \\
155(7 \cdot 8)\end{array}$ & $\begin{array}{l}8105 \\
1399\end{array}$ & $\begin{array}{l}208(2 \cdot 6) \\
128(9 \cdot 1)\end{array}$ & $\begin{array}{r}40017 \\
6674\end{array}$ & $\begin{array}{r}1078(2 \cdot 7) \\
555(8 \cdot 3)\end{array}$ \\
\hline
\end{tabular}

^ Excluding women given routine pre-employment screens as requested by occupational health clinics.

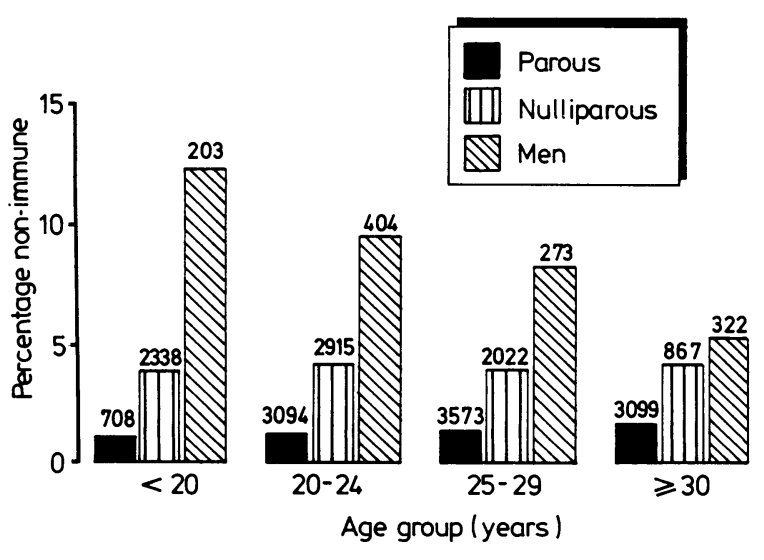

FIG 1-Proportions of pregnant women and men seronegative to rubella according to age in 1984 . Figures on columns are numbers tested in each group.

Information on parity was available for 18616 women screened, of whom $56 \%$ were parous. In all $1.4 \%$ of parous women were seronegative compared with $4 \cdot 2 \%$ of nulliparous women and $8 \cdot 6 \%$ of men. The difference between parous and nulliparous women was highly significant in all age groups (fig 1). Within each parity group the proportion seronegative did not vary with age. In parous women there was no difference between those in their second and those in subsequent pregnancies. In all age groups the proportion of men who were seronegative was higher than that of nulliparous women; the difference was most pronounced (threefold) in the under 20 age group. samples from occupational health clinics, only $181(3 \cdot 8 \%)$ were seronegative. By contrast, of the 6674 samples received from general practitioners, family planning clinics, or other sources, $555(8 \cdot 3 \%)$ were seronegative-nearly three times the proportion in the samples from pregnant women (table II). The proportion of non-pregnant women who were seronegative showed little variation with age and remained constant irrespective of the numbers screened each month.

The number of requests for prevaccination screening (other than from occupational health clinics) rose in the summer of 1983 , when rubella notifications in Manchester increased. Requests for screening of pregnant women in contact with rubella also increased at that time, confirming the occurrence of a local outbreak (fig 2). Requests for prevaccination screening also doubled in December 1983, when rubella was not prevalent. The rise began in the week of 28 November, coinciding with the start of the campaign; requests began to fall in February 1984 but increased in the summer, when rubella was again prevalent. Measures taken by two local health authorities to increase rubella screening in their staff and factory employees resulted in a further rise in October and November 1984. Routine requests for pre-employment screening from occupational health clinics did not reflect either the occurrence of local rubella outbreaks or the effect of national publicity.

\section{VACCINATION}

Post partum-A total of 1306 women for whom vaccination was recommended post partum were followed up at seven hospitals and information obtained for all but 21 . Of the 1254 women who went to term, $1066(85 \%)$ were vaccinated in hospital before discharge (table III); the proportion vaccinated was not affected by the length of stay. One hospital (D) had no policy for postpartum vaccination at the outset, but this changed as a result 
of action taken by the study nurse. In the six other hospitals the proportion of women vaccinated varied little over the period. Only four of the 31 nonimmune women who were admitted for abortion were vaccinated before discharge. Of the 215 women not vaccinated in hospital, 72 were vaccinated after discharge, all but six as a result of action by the study nurse. Of the 143 women who remained unvaccinated, 59 no longer needed to be -42 because of sterilisation, four because of rubella infection, and 13 because on retesting they were considered to be immune. Thus of the 1285 women screened antenatally for whom postpartum vaccination was advised, $84(6.5 \%)$ remained unvaccinated and at risk in a later pregnancy. Without the intervention of the study nurse this figure would have been $150(11 \cdot 7 \%)$.

TABLE III-Vaccinations given post partum and before discharge in seven hospitals, November 1983 to December 1984

\begin{tabular}{lccccc}
\hline & \multicolumn{2}{c}{ Delivered } & & \multicolumn{2}{c}{ Aborted } \\
\cline { 2 - 3 } \cline { 5 - 6 } Hospital & $\begin{array}{c}\text { No } \\
\text { followed up }\end{array}$ & $\begin{array}{c}\text { No (\%) } \\
\text { vaccinated } \\
\text { in hospital }\end{array}$ & & $\begin{array}{c}\text { No } \\
\text { followed up }\end{array}$ & $\begin{array}{c}\text { No } \\
\text { vaccinated } \\
\text { in hospital }\end{array}$ \\
\hline A & 212 & $166(78)$ & & 4 & 0 \\
B & 235 & $200(85)$ & & 4 & 0 \\
C & 51 & $46(90)$ & & 1 & 1 \\
D & 113 & $78(69)$ & & 14 & 0 \\
E & 325 & $299(92)$ & & 5 & 2 \\
F & 140 & $110(79)$ & & & \\
G & 178 & $167(94)$ & & 31 & 4 \\
\hline Total & 1254 & $1066(85)$ & & & \\
\hline
\end{tabular}

*Information from April 1984

TABLE IV-Confirmed rubella infections during pregnancy, Manchester $1983-4$

\begin{tabular}{lcccccc}
\hline & $\begin{array}{c}\text { Total } \\
\text { pregnant women } \\
\text { susceptible }\end{array}$ & $\begin{array}{c}\text { No }(\%) \\
\text { infected }\end{array}$ & \multicolumn{4}{c}{ No of infections by quarter of year } \\
\cline { 5 - 7 } Year & 1519 & $30(2 \cdot 0)$ & 8 & 2nd & 3rd & 4th \\
\hline 1983 & 1107 & $27(2 \cdot 4)$ & 4 & 20 & 3 & 0 \\
1984 & & & & & &
\end{tabular}

Non-pregnant women-Of 578 non-immune women screened in 1984 and followed up, information was obtained for 536 (93\%). In all, $376(65 \%)$ had been vaccinated, with a mean interval between screening and vaccination of six weeks. More patients referred by general practitioners had been vaccinated $(72 \%)$ than those referred from occupational health clinics $(56 \%)$ or other sources $(66 \%)$. Of the 160 not vaccinated, 22 refused and a further four acquired rubella; $28(5 \%)$ were subsequently vaccinated as a result of the inquiry. The remainder had either failed to keep the appointment, left employment, or changed their doctor. Analyses of age and parity of 249 nonimmune women showed that $86 \%$ were nulliparous and that nearly half of these were too old to have been offered vaccine at school.

\section{CONTACT AND DIAGNOSTIC TESTING}

Details of patients tested because of contact or suspected rubella in 1984 were available from the Manchester Public Health Laboratory. A total of 976 were pregnant women from the catchment area of the three laboratories; 899 had been in contact with rubella and 77 presented with a rash or other symptoms suggestive of the disease. Of the women tested after contact, 58 $(6.5 \%)$ were non-immune and in $7(1 \%)$ acute rubella was confirmed; of those presenting with symptoms, $13(17 \%)$ had rubella confirmed. A further seven pregnant women had rubella confirmed by the North Manchester Regional Virus Laboratory, giving a total of 27 cases in the local pregnant population during 1984 . Ten of the 15 women infected during the first 16 weeks of pregnancy chose to have their pregnancies terminated. In all, 17 pregnancies continued to term. Congenital infection (IgM antibody in cord blood) was diagnosed in six infants, none of whom had symptoms at birth.

Sixteen $(59 \%)$ of the 27 women infected during 1984 were parous, giving an attack rate of $5 \%$ in the 320 parous women susceptible during 1984; the rate in the 787 susceptible nulliparous women was $1.4 \%$. Two parous women had documented evidence of past adult vaccination (one with Almevax, one with Cendevax). Two had been screened in a previous pregnancy but had refused vaccine, while another had not been vaccinated post partum because she had refused contraception.
In 1983 acute rubella was confirmed in 30 pregnant women in the local population. Of the 21 infected during the first 16 weeks of pregnancy, 16 had a therapeutic abortion. Congenital infection was diagnosed in five infants, of whom one had symptoms at birth and a second was subsequently found to be deaf.

In both 1983 and 1984 most of the infections occurred in the April to June quarter (table IV). In all, $4 \%$ of pregnant women in the area required serological investigation for contact or suspected infection with rubella during 1984.

\section{Discussion}

This study shows that in 1984 fewer than $3 \%$ of 40000 pregnant women in the Manchester area were susceptible to rubella. By contrast, nearly $9 \%$ of men were susceptible, a figure similar to the $10 \%$ of pregnant women reported in Britain before vaccination began. ${ }^{1+}$ The difference in susceptibility between nulliparous women and men of the same age was greatest in the under 20 age group and must largely be due to the vaccination of schoolgirls. Immunity in younger women is likely to increase further, since in Manchester acceptance of vaccination by girls of 11 years has exceeded $90 \%$ since $1979 .{ }^{15}$ The difference in susceptibility between men and nulliparous women too old to have been vaccinated at school indicates that vaccination before pregnancy has also had considerable effect. The prevalence of antibody in men increased with age, suggesting that acute rubella in men is not uncommon and must present a risk to non-immune pregnant women.

The impact of postpartum vaccination is reflected in the threefold difference in susceptibility between parous and nulliparous women of the same age. Although the greater exposure to infection in parous women may have been contributory, the effect of this must be small compared with that of postpartum vaccination, which in Central Manchester in 1981 was given to $90 \%$ of seronegative mothers before discharge. ${ }^{15}$ In our study $85 \%$ of non-immune women were vaccinated in hospital, some hospitals exceeding the DHSS target of $90 \%$. We found, however, that without the intervention of the study nurse few women would have been vaccinated after discharge, since there was no effective link between hospital and general practitioner. Further omissions included a lack of vaccination policy for women admitted for abortion or being treated for infertility.

An increase in requests from general practitioners for screening non-pregnant women reflected an immediate-though short lived -response to the national campaign, and local initiatives and rubella outbreaks produced a similar effect. Susceptibility to rubella among the non-pregnant women screened was three times that in the pregnant population; clearly screening non-pregnant women identifies many who have missed both school and adult vaccination. Over a quarter, however, were not subsequently vaccinated, and follow up by the laboratories increased the vaccination rate by only $5 \%$. Routine pre-employment testing, which accounted for nearly half the requests for screening non-pregnant women, identified few susceptible women. Only half of these were subsequently vaccinated, confirming previous findings. ${ }^{16}$

The reduction in the number of susceptible women in the local pregnant population in recent years must have prevented many infections in pregnancy. Nevertheless, during the 1983-4 outbreaks in Manchester, both smaller than that of 1978, rubella was confirmed in over $2 \%$ of susceptible pregnant women. The risk was greatest when outbreaks were at their height; no infections were reported in the winter, when rubella was not prevalent. For nonimmune women the risk of infection was three times greater for those with children than for those in their first pregnancy. The large number of pregnant women who sought diagnostic investigation after contact shows the anxiety aroused when rubella is prevalent. Over $93 \%$ of those investigated proved to be immune, but this increase in laboratory work load is inevitable so long as the wild virus continues to circulate. The 57 infections in this study-out of a total of nearly 700 reported to the Communicable Disease Surveillance Centre by laboratories in England and Wales in 19834-were diagnosed at the time of infection, so giving the woman the option of having her pregnancy terminated. Clearly the diagnosis 
and termination of infected pregnancies are still essential factors in preventing congenital rubella syndrome. In asymptomatic cases with no known contact, however, an affected baby may be the first sign.

The policy of selective vaccination in Britain has aimed at increasing immunity in the childbearing population rather than reducing the overall incidence of rubella. In the Manchester area a high degree of immunity has now been achieved through levels of school and postpartum vaccination approaching those recommended. Preliminary results from other laboratories participating in the study show immunity in excess of $97 \%$ in populations of pregnant women elsewhere in the country. Selective vaccination has had considerable effect, but it is clear that $1-2 \%$ of women will inevitably remain susceptible, either because they miss or refuse vaccination or because they fail to respond to vaccine. Our findings show the consequences of allowing wild rubella virus to circulate while even this small proportion of pregnant women remains susceptible.

Although this report relates to one area only, the implications are that even when the present policy is well implemented congenital rubella syndrome will not be eliminated and infection in pregnancy will continue at an unacceptable level. Vaccination of the target population should undoubtedly continue, but we believe that the policy should be supplemented by mass vaccination of infants and preschool children of both sexes to reduce circulation of the virus and thereby the risk of contact in pregnancy. The immediate and long term effects would depend both on the quality and duration of vaccine induced immunity and on the acceptance of vaccine in infancy and childhood. Discussion of these topics is outside the scope of this paper and will be presented elsewhere. If, however, the proposed additions were to be adopted the monitoring system described here would provide the means of assessing the results of the change in policy.

The study was funded by the Office of the Chief Scientist. We thank John Lobb and Dr Hilary Tillett for computer and statistical work, and Margaret Ridehalgh (Manchester Public Health Laboratory) and Denise McDonnell (North Manchester Regional Virus Laboratory) for clerical help.

\section{References}

1 Department of Health and Social Security. Rubella prophylaxis. London: DHSS, 1970. (Circular 9/70.)

2 Department of Health and Social Security. Rubella immunisation. London: HMSO, 1983. $(\mathrm{HN}(83) 33$.)

3 Dudgeon JA. Immunisation policies. Br Med f 1983;286:1511

4 Department of Health and Social Security. Rubella immunisation. London: DHSS, 1972. (Circular 17/72.)

5 Peckham CS, Marshall WC, Dudgeon JA. Rubella vaccination of schoolgirls: factors affecting vaccine uptake. $\mathrm{Br}$ Med $\mathcal{F}$ 1977;i:760-1.

6 Smithells RW, Sheppard S, Holzel H, Dickson A. National congenital rubella surveillance programme 1 July 1971-30 June 1984. Br Med f 1985;291:40-1.

7 Office of Population Censuses and Surveys. Abortion statistics series $A B$ No 51978 . London: HMSO, 1980.

8 Office of Population Censuses and Surveys. Abortion statistics series AB No 6 1979. London HMSO, 1981

9 Chief Medical Officer. Rubella vaccination. London: DHSS, 1979. (CMO(79)6.)

10 Department of Health and Social Security. Rubella vaccination in schoolgirls. London: HMSO, 1985. (SBL 607.)

11 Chief Medical Officer. Congenital rubella syndrome. London: DHSS, 1983. (CMO(83)4.)

12 Chief Medical Officer. Congenital rubella syndrome. London: DHSS, 1983. (CMO(83)5.)

13 Chief Medical Officer. National rubella campaign. London: DHSS, 1983. (CMO(83)8.)

14 Public Health Laboratory Service Working Party on Rubella. Studies on rubella in pregnancy. $B r$ Med f 1968;iii:203.

15 Jones AE. Implementation of the rubella vaccination programme in Manchester. Community Med 1983;5:287-94.

16 Jachuck SJ, Bound CL, Jones CE. Role of the occupational health service in screening and increasing the uptake of rubella immunisation. Br Med f 1985;290:119-22.

(Accepted 13 August 1985)

\title{
For Debate ...
}

\section{Cardiopulmonary resuscitation-American style}

\author{
RICHARD O CUMMINS, MICKEY S EISENBERG
}

The Fourth World Congress on Emergency and Disaster Medicine was held recently in Brighton on the eve of a national campaign to train people in communities in cardiopulmonary resuscitation. The Resuscitation Council of the United Kingdom, the British Heart Foundation, and the British Association for Immediate Care sponsor this scheme. People from more than 30 countries attended. These countries use a rich variety of approaches to emergencies that occur out of hospital, yet few have adopted community training schemes for cardiopulmonary resuscitation. At Brighton several concerns were expressed repeatedly. Can people trained in such schemes do harm if they perform resuscitation on people who are not in cardiac arrest? Is vigorous resuscitation harmful to people whose hearts have stopped beating? Can such schemes train people

Department of Medicine, University of Washington, Seattle

RICHARD O CUMMINS, MD, MPH, associate professor

MICKEY S EISENBERG, MD, PHD, associate professor

Correspondence to: Dr Richard O Cummins, University Hospital, RC-02, Seattle, Washington 98195 , USA. to an adequate level of skill that will be remembered over time? Does cardiopulmonary resuscitation really save lives?

In our experience community training schemes for cardiopulmonary resuscitation are the essential foundation for improving survival from cardiac arrest that occurs out of hospital. Such schemes were begun over 14 years ago by Cobb and his colleagues in Seattle. ${ }^{2}$ By 1985 over 450000 people had been trained in Seattle and adjoining King County. Guided by this training, people in King County initiate resuscitation for half of all cardiac arrests. We have recorded detailed information on over 3000 patients who had a cardiac arrest in King County, all of whom had cardiopulmonary resuscitation provided by people in the community or emergency medical personnel, or both. ${ }^{3}$ Can this American experience answer some of the concerns of those who attended the Brighton meeting?

\section{"False positive" issue}

Several times at Brighton we heard the comment: "Seattle and King County, Washington, are the best places in the world to have a heart attack but the worst places in the world to have a faint!" Does harm occur when overzealous people administer cardiopulmonary resuscitation to people who are not in complete cardiac arrest-for example, victims of syncope and drug 